\title{
UN APORTE AL ESTUDIO DEL VOTO FEMENINO EN COSTA RICA ${ }^{1}$
}

\section{A CONTRIBUTION TO THE STUDY OF THE FEMALE VOTE IN COSTA RICA}

\author{
Natalia Carballo Murillo*
}

\begin{abstract}
RESUMEN
Esta investigación es un aporte a los estudios sobre el voto femenino en Costa Rica, mediante el análisis de las peticiones de la Liga Feminista $y$ de otras mujeres, los discursos pronunciados entre 1948-1952 en periódicos y en las actas de la Asamblea Legislativa. Se encontró que en las peticiones se hace énfasis en las capacidades de la mujer y en las discusiones de aprobación se referían a su imagen romántica, estereotipada e inocente. Una vez aprobado el voto, se valida a la mujer como sujeto de decisión en las urnas.
\end{abstract}

PALABRAS CLAVE: HISTORIA * COSTA RICA * SUFRAGIO FEMENINO * MOVIMIENTO DE LIBERACIÓN FEMENINA

\section{ABSTRACT}

This research seeks to contribute to the studies of the female vote in Costa Rica by analyzing the petitions of the Feminist League and other women, speeches that were pronounced from 1948 to 1952 in newspapers and in the records of the Legislative Assembly. It was observed that petitions emphasized women's abilities and, in the approval discussions, their romantic, stereotypical and innocent image was validated. Once the vote is approved, women are ratified as decision-making subjects at the ballot box.

KEYWORDS: HISTORY * COSTA RICA * WOMENS SUFFRAGE * WOMENS LIBERATION MOVEMENT

1 Este artículo es producto de la contratación nro. 2008CD-000572-01 con el Instituto Nacional de la Mujer de Costa Rica (INAMU).

Sede del Pacífico de la Universidad de Costa Rica, Costa Rica.

natalia.carballomurillo@ucr.ac.cr / natalia.carballo.m@gmail.com 


\section{INTRODUCCIÓN}

En el marco de la celebración de los setenta años de la aprobación del voto femenino, y con la intención de aportar a su estudio ${ }^{2}$, este artículo tiene dos objetivos, relacionados entre sí. Primero, evidenciar la importante participación de la mujer en la política, haciendo un análisis a las peticiones hechas al Congreso para su aprobación, tanto de la Liga Feminista como de peticiones independientes. Segundo, analizar las discusiones alrededor del voto femenino. Para ello se analizaron las peticiones, los discursos de los diputados para apoyarlo o refutarlo, y lo publicado en los periódicos sobre el tema.

Con el fin de seguir una línea cronológica que permita entender el desarrollo de los acontecimientos, se presentarán el análisis y la descripción de las solicitudes de aprobación del sufragio femenino por parte de la Liga Feminista, $y$ de otras mujeres al Congreso. Luego se analizará la época de la aprobación, de acuerdo con los discursos pronunciados entre 19481952 en periódicos y en las actas de la Asamblea Legislativa. Para el año 1948, se estudiará solamente las discusiones en los periódicos $L a$ Prensa Libre, La Nación y el Diario de Costa Rica, por lo cual se revisaron en total 9 artículos. Para los otros años se utilizaron ambas fuentes.

\section{PETICIONES DE LA LIGA FEMINISTA, Y DE OTRAS SEÑORAS Y SEÑORITAS}

La Liga Feminista dio sus primeros pasos en 1921 como un pequeño comité inicial de mujeres derivado del Auxiliar de Señoras de los Estados Unidos. Esta fue una decisión tomada en Nueva York a iniciativa de Mrs. Ligget, presidenta del Comité Feminista de aquella nación (Chacón, 1984). Fue dos años después, el 12 de octubre de 1923, en una ceremonia en el

2 Esta investigación es un aporte a lo investigado por otras autoras como Carla Morales Rojas, Hilda Villalobos Palma, María Pía Montealegre Llobet, Eugenia María Zamora Chavarría, Macarena Barahona Riera, Diana Senior Angulo, Eugenia Rodríguez Sáenz, entre otras.
Colegio de Señoritas que se funda oficialmente la Liga Feminista Costarricense. Surgió como una filial de la Liga Internacional de Mujeres Ibéricas e Hispanoamericanas, organización con sede en España, cuyos objetivos giraban en torno a la lucha por la consecución del voto para las mujeres, el desarrollo de actividades de bienestar social y campañas antialcohólicas (Flores, 2001).

La primera junta directiva tuvo a Ángela Acuña como presidenta, Esther de Mezerville como vicepresidenta y Ana Rosa Chacón como secretaría, la mayoría de las fundadoras de esta organización fueron maestras, algunas graduadas del Colegio de Señoritas, $y$ sus integrantes, en su mayoría, fueron mujeres de clase media y alta, intelectuales, maestras, estudiantes y graduadas del mencionado colegio (Rodríguez, 2005).

Ocho años después de su fundación (15 de junio de 1931), el 4 de mayo de 1939, la Liga presentó cinco peticiones ${ }^{3}$. La petición del 15 de junio de 1931 (Archivo Nacional de Costa Rica [ANCR], s.f.b) es a nombre de varias señoras y señoritas, en la cual solicitan de forma simple ${ }^{4}$, agregar el voto femenino al artículo I de la Ley de Elecciones ${ }^{5}$, tratando de hacer ver la incorporación de dicha modificación como algo sencillo, sin mucha demora o discusión. Igualmente,

3 Los documentos que contienen las solicitudes están en: Archivo Nacional de Costa Rica. Actas de la Asamblea Nacional Constituyente. Fondo Congreso nro. 17114 y nro. 18811. Las fechas de dichas peticiones son: 15 de junio de 1931, 23 de junio de 1932, 10 de mayo de 1934, 31 de julio de 1934 y 4 de mayo de 1939.

4 En el documento se expone: "Nosotras las infrascritas, con respeto exponemos: Un simple agregado al artículo I de la Ley de Elecciones, nos colocaría en la condición de emitir el voto, con la justicia sobrada que nos asiste, sin complicar en lo más mínimo la labor parlamentaria que en materia de reforma electoral está por iniciarse, ni muchos menos entrar a detenidos estudios sobre la constitución, porque todo quedaría aclarado con la sencilla modificación" (subrayado propio) (ANCR, s.f.b, p.3).

$5 \quad$ El artículo I decía en ese momento: "El derecho de sufragio es esencialmente político, y podrán ejercitarlo los ciudadanos (hombres)" (Ley nro. 15, Asamblea Legislativa, 26 de setiembre de 1927). 
argumentan que a una mujer preparada no se le puede igualar intelectual ni moralmente con un grupo de hombres que no tiene una preparación cívica ni responsabilidad, pero aún así emiten su voto. Esto deja ver a la educación como un elemento distante al sufragio, puesto que el hombre puede llegar a ser un ignorante, es decir, solo por ser hombre no significa que sea más inteligente ni moralmente superior que una mujer.

Asimismo, cuestionan cómo Costa Rica siendo un país con todas las características necesarias para ser Estado, se niega a darle el voto a la mujer; cómo va a negar cubrirse de orgullo en la búsqueda de una mejor orientación, al incluir a todos los miembros del país (hombres $y$ mujeres). Exponen el otorgamiento del voto como un mejoramiento a la condición de la mujer $y$ de las futuras generaciones, lo cual, como consecuencia, las llevaría a defender al Estado para resguardar la constitución, la paz interior, las libertades y las instituciones. Es decir, ver a la mujer como un baluarte de ayuda al hombre para defender y mejorar al Estado, no obstante, para ello era necesario el primer paso: el otorgamiento del voto.

En el párrafo anterior se plantea que no solamente la educación basta para formar al ciudadano, sino que debe dársele la responsabilidad de saber elegir y luchar para hacer un bien a la Patria y a la familia, por lo tanto, no solo con educar a la mujer es suficiente, sino se le debe otorgar responsabilidad política. De igual manera, se apela a elevar el nivel intelectual de la mujer por medio del voto, aumentando los votantes, colaborando en una patria común sin exclusiones. Finalmente, el voto ayudaría a probar las capacidades de la mujer.

Además, esta solicitud se convierte en un desafío para la capacidad de las mujeres, ellas son capaces de tener responsabilidades $y$ asumir el derecho al voto de la mejor manera por el bien del Estado y de la patria. Incluye otros elementos como la responsabilidad y el orgullo del Estado, la diferencia entre hombres sin educación y mujeres educadas, así como, retoma el tema de la capacidad y la moral. Llama la atención la frase de conclusión, en la cual se lee: "si así lo hiciéremos que dios nos ayude, y si no, que él y la patria nos lo demande". La frase compromete al gobierno a cumplir con lo solicitado, como si el voto femenino fuera un pedido de la patria y del Estado, por lo que de no aprobarse esto sería una falta digna de reproche.

Adjunto a la petición se incorpora el cambio que debe hacerse al artículo, además de la lista de requisitos a cumplir por las mujeres que pretendan ejercer el voto (ANCR, s.f.b, p.4). En estas primeras peticiones, la búsqueda del voto se hacía con restricciones de quiénes lo podrían ejercer. Un año después, el 23 de junio de 1932 (ANCR, s.f.a) se da una nueva solicitud, son tres los argumentos: 1) el voto como una ayuda a la mujer y a su condición ${ }^{6}$; 2) una ayuda que se le brinda al Estado; y 3) se apela nuevamente al orgullo, en este caso, de los diputados, "será para los señores representantes de este período legislativo una gloria que quede en los anales de nuestra vida pública, consagrar para siempre el sufragio femenino" (ANCR, s.f.a, p.1). En 1934, la Liga Feminista hace una solicitud indicando:

No entraremos en más comentarios o explicaciones porque el asunto ha sido de sobra bien tratado aquí y en todas partes. Seguir teorizando no tiene resultado positivo. Lo que sí agradeceríamos mucho es que la mesa ordene la lectura de esos escritos para refrescar en la memoria de los señores diputados la forma $y$ condiciones en que pedimos ese voto (ANCR, s.f.b, p.6).

A diferencia de las solicitudes anteriores, esta no tiene argumentos de convencimiento, al no considerarlos necesarios.

Para el 31 de julio de 1934, se reclama que la discusión en el Congreso sea la elección del presidente de la República sin haber solucionado algo tan importante como lo referente al voto, por tal motivo se da nuevamente una carta de la Liga Feminista para reclamar sobre

$6 \quad$ En el documento se expone: "Pedíamos esa reforma de un modo restringido con el objeto de dar a muchas de las mujeres costarricenses la oportunidad de salir de su medio ambiente estrecho y estéril" (ANCR, s.f.a, p.1). 
la no discusión en el Congreso del voto femenino, que tan reiteradas veces había sido solicitado (ANCR, s.f. b, p.9).

La petición del 4 de mayo de 1939 (ANCR, s.f.b) es el resultado del Primer Congreso Centroamericano Femenino de Educación, celebrado el 14 de setiembre de 1938. En este se tomó la decisión de seguir gestionando el voto para la mujer. En dicho documento hay un recuento de la condición de la ciudadanía de la mujer desde la constitución de 1848 y el proyecto de ley para enmendar el artículo 20 de la Ley de Elecciones. En un documento anexo a este, se presentan los argumentos esbozados por parte de las mujeres de la Liga Feminista, los cuales se analizaran, ya que coinciden con los argumentos de diez años después, los esbozados en los años anteriores a la aprobación del voto en 1949. Por ejemplo, el aspecto de la democracia "dentro del verdadero sentido de la democracia a la mujer no puede negársele lógicamente la participación que le corresponde en los negocios públicos" (ANCR, s.f.b, p.6), y la negación del hecho que la política resta virtudes propias de la mujer "la objeción de que las mujeres pueden perder las virtudes domésticas y su propia condición femenina porque adquieran el derecho político" (ANCR, s.f.b, p.7), ya que "la mujer contribuye al igual que el hombre al pago de todas las cargas impuestas por el Estado desde luego es justo que tenga un legítimo interés en el resguardo de las instituciones públicas" (ANCR, s.f.b, p.8).

Los otros argumentos giran en torno a desmentir la docilidad de la mujer, plantean que la mujer como el hombre pueden padecer debilidades "pero es bien sabido que toda persona de carácter, cualquiera que sea su sexo, se rige en su conducta por la virtud de sus ideas" (ANCR, s.f.b, p.7). Posteriormente, se presenta la aclaración autenticada por "un laborioso estudioso el licenciado don Pedro Pérez Zeledón 7 , expositor autorizado de grata memoria para la patria", lo cual permite argumentar cómo la Constitución de la República no niega a las mujeres el

$7 \quad$ Diputado que durante el período en estudio, fue uno de los políticos liberales que se pronunció a favor del voto femenino. derecho político, "que en el nombre masculino plural COSTARRICENSE entran por igual, gramatical y lógicamente ambos sexos, la ciudadanía de la mujer es absolutamente indiscutible" (ANCR, s.f.b, p.10).

Tres de estas cartas de solicitud están a nombre de la Liga Feminista ${ }^{8}$, las otras están a nombre de varias señoras y señoritas. Un elemento para destacar de dichas peticiones es su forma exclusiva para mujeres con cierto nivel educativo, de preparación o dueñas de empresas. Igualmente, se rescata el papel de la señora Ángela Acuña, en su función de abogada $y$ mujer a favor del voto femenino, lo cual evidencia el gran esfuerzo y compromiso con la lucha por el reconocimiento de la igualdad política entre hombres y mujeres. Ella es la encargada de autenticar las solicitudes descritas con anterioridad.

Asimismo, fue importante la participación del grupo de maestras del Partido Comunista, fundado en 1931. Dichas mujeres fueron estudiantes o maestras del Colegio Superior de Señoritas y de la Escuela Normal durante los años 20, en los cuales las mujeres organizadas lucharon contra el "trust" eléctrico y los contratos bananeros entre el Estado costarricense $y$ la United Fruit Company. Además de llevar consigo las experiencias de dichos años, fueron hijas del contexto internacional como el agotamiento del liberalismo y las graves contradicciones sociales y políticas que surgieron durante la depresión económica iniciada en 1929 (Herrera, 2005). Entre las maestras destacadas vinculadas con el Partido Comunista cuentan María Isabel Carvajal (Carmen Lyra), Luisa González, Adela Ferreto, Stella Peralta, Emilia Prieto, María Alfaro de Mata, Hortensia Zelaya, Angela García, María Odilia Castro, Esther Silva, Lilia Ramos, entre otras (Herrera, 2005).

$8 \quad$ La autora Ana Lorena Flores en su tesis Ni histéricas, ni reinas...ciudadanas: mujeres y politica en Costa Rica, 1940-1949, menciona: "La principal reivindicación de la Liga Feminista Costarricense fue el sufragio femenino" (Flores, 2001, p.50). 


\section{DISCUSIONES SOBRE EL VOTO FEMENINO}

De manera obvia, los argumentos esbozados de 1948 a 1952, con respecto a la aprobación del voto femenino, se pueden dividir en dos, los que están a favor y los que están en contra; pero ¿cuáles son los planteamientos expuestos por ambos sectores?, a continuación se expondrán ambas posiciones.

En un artículo de $1948^{9}$, el señor Ulate se expresó en el sentido de que "la mujer puede participar, como electora y como elegida en la próxima constituyente" (31 de mayo de 1948, p. 1 y 8). Nótese el carácter de posibilidad más que de determinación. Días después de su publicación, el señor Rafael A. Solís (1948) publica un artículo, en el cual hace referencia a la conveniencia o no del voto femenino, planteando como la propuesta del voto cobra importancia por ser Otilio Ulate quien la promulga, aunque enfatiza el hecho de que algunas mujeres ya habían realizado esta petición tiempo atrás. Asimismo, menciona que es un hombre, pero no cualquier hombre, sino el mismo Otilio Ulate, quien en lo próximo se convertiría en el presidente del país.

El trasfondo del artículo es proponer que la decisión del voto debe recaer sobre las propias mujeres, porque de darlo el hombre estas podrían no aceptarlo. En esta cita no se deja de lado el carácter "rebelde" impuesto a la mujer:

... claro está que el hombre tiene en sus manos el derecho de decirle a la mujer que puede votar. Con solo modificar la constitución o la ley que refrena los eventos electorales. ¿Pero de hacerlo así la mujer aceptará complacida ese derecho que le otorga el hombre? (Solís, 3 de junio de 1948).

$9 \quad$ En 1917, se dan las primeras discusiones de los diputados sobre el derecho de la mujer a ejercer el voto, así como de los requisitos que debían cumplir estas para poder ejercerlo, véase: (Fernández, 1985, pp. 15-21). Eugenia Rodríguez en su artículo "La lucha por el sufragio femenino en Costa Rica (1890-1949)", identifica a Sara Casal como una de las principales mujeres interesadas en el asunto del voto femenino, véase: (Rodríguez, 2005) y (Casal, 1925).
Hay otros argumentos destacados por este autor $y$ presentes en otros artículos. Por un lado, lo meritorio de darle el voto a la mujer porque ella se lo ha ganado, como fue expuesto por el señor José María Figueres Ferrer en un discurso, en el cual acentuaba la importancia de las actuaciones políticas de las mujeres en años anteriores, haciendo especial referencia a la dictadura de los Tinoco (La sublime y heroica mujer costarricense cívicamente nos ha igualado, pero su voto debe ser optativo, 3 de junio de 1948). Un tiempo después, en el acta 92 del 20 de junio de 1948, en la cual se da la aprobación del sufragio femenino, surge la idea de darlo por agradecimiento, merecimiento o conquista por su participación en los acontecimientos políticos del pasado ${ }^{10}$, es un argumento estrechamente relacionado con el reconocimiento a su patriotismo ${ }^{11}$.

De acuerdo a los argumentos Solís, se considera la intromisión de la mujer en la política como un elemento de corrupción ${ }^{12}$,

10 El planteamiento de la mujer merecedora del voto por mérito es expuesto por varios de los representantes, algunos ejemplos serían las palabras del señor Ortiz, quien "agregó que los acontecimientos últimos vividos por el país, en los que las mujeres tuvieron una decidida participación, son suficientes para otorgar a las mujeres el derecho al sufragio" (Asamblea Legislativa, Archivado A39 E7623, p. 4). Asimismo, el representante Baudrit Solera "agregó que aparte de muchas otras razones que sobra enumerar y en vista de los sucesos políticos acaecidos en Costa Rica en los últimos años (...) tan solo recordando acaso los gestas del 15 de mayo y del 2 de agosto, debidas al coraje y a la dedicación de las mujeres costarricenses" (Asamblea Legislativa, Archivado A39 E7623, pp. 4-9).

11 Propuesta defendida en los planteamientos del representante Esquivel y Fournier (Asamblea Legislativa, Archivado A39 E7623, p.5).

12 ¿A ellas les placerá tomar participación directa en eventos que en muchas oportunidades embriagarán los sentimientos y desenfrenan las ambiciones? ¿No temerán acaso que el día de mañana sus sentidos, tan diáfanos ahora, se nublen con esa fiebre traidora que es la política? ¿No les dolerá acaso dejar su sitial absolutamente femenino trono hogareño, para arribar a las turbulentas aguas de las pasiones políticas? ¿No temerán el caer en el periodo negro en que naufragan 
se dignifica a la mujer desvirtuando la política o se desvirtúa la política para dignificar a la mujer.

El discurso del presidente Ulate, quien tres años antes mencionaba la posibilidad de la participación de la mujer, alaba su intervención en las votaciones. En su discurso de aceptación explica elementos no tomados en cuenta antes: la capacidad intelectual y moral de la mujer, ya no se habla del civismo de la mujer sino de su cultura cívica, "su derecho de ir a las urnas, dijo, le es propio por su capacidad intelectual y moral y por su valioso aporte a la solución de crisis políticas" (Esperanzado el presidente Don Otilio Ulate en la dignificación de los procesos electorales, 22 de octubre de 1951, p.16), ya no es por su participación directa en acontecimientos políticos, sino por aportar solución en las crisis políticas.

Relacionado con los discursos políticos es importante rescatar la Columna del Partido Social Demócrata: "Partido Social Demócrata ha decidido dedicar una serie de columnas a hablar sobre el voto femenino. Es una labor que se ha impuesto por considerarla necesaria, no por interés político sino por su transcendencia cívica" (Columna del Partido Social Demócrata, 2 de agosto de 1951, p.6). Sin cuestionar la intención política de la columna, resulta de sumo interés este tipo de publicaciones para conocer por cuánto tiempo tuvieron el espacio y cuántas notas se dedicaron en específico al sufragio femenino. En la primera entrega, se observan ideas nada innovadoras sobre el tema, tratadas en líneas anteriores, tales como, el reconocimiento a la labor cívica y a la faena en los acontecimientos políticos del pasado (Columna del Partido Social Demócrata, 2 de agosto de 1951), sin embargo, sí hay un factor no contemplado en otros discursos, "el deseo de cumplir los compromisos internacionales adquiridos por Costa Rica en la Organización de las $\mathrm{Na-}$ ciones Unidas para conceder el voto femenino" (Columna del Partido Social Demócrata, 2 de agosto de 1951, p.6).

muchos hombres, por equívocos naturales que ocurren a todo mortal?" (Asamblea Legislativa, Archivado A39 E7623, pp. 4-9).
La segunda entrega, una semana después, habla nuevamente de la participación de las mujeres en los eventos de 1917 y 1943, pero con un tono más enfático:

... sin embargo, por gloriosas que sean esas fechas, representan únicamente la reacción nacional en momentos de crisis. Falta aún que esa intervención, traducida en el ejercicio del derecho del sufragio, sea mantenida con plena conciencia en tiempos de paz; que cuando llegue la hora las mujeres de Costa Rica se encuentren preparadas, legal e institucionalmente para dar su voto ... por ello se impone el llamamiento a todas las mujeres para que se preparen a cumplir fielmente con la obligación del sufragio (Columna del Partido Social Demócrata, 9 de agosto de 1951, p.6).

En cierto sentido, se desacredita la participación de la mujer en dichos acontecimientos políticos con el fin de poner de manifiesto que la verdadera labor debe ser en tiempos de paz, votando.

La tercera entrega no se dio, en la cuarta se hizo un llamado a la población para ayudar a los damnificados de Paraíso y Orosí (Columna del Partido Social Demócrata, 30 de agosto de 1951), en la quinta, que fue en setiembre, se habló sobre la autonomía municipal (Columna del Partido Social Demócrata, 20 de setiembre de 1951). De dicho mes hasta el 18 de octubre, no se publican más columnas del Partido Social Demócrata. La publicación es bastante irregular y dedica al voto femenino solamente dos columnas.

En este punto resulta importante rescatar la opinión de Lía Quirós Orozco (1 de julio de 1948), quien en su artículo menciona cómo el sufragio no afecta la feminidad $y$, además de recalcar el merecimiento de la mujer al voto debido a sus actuaciones en las crisis políticas, plantea que el voto debe ir acompañado de la educación de las mujeres para una mejor elección:

... tengo el concepto de que la mujer debe preparársele para la función del sufragio. Debe adquirir junto con los 
conocimientos elementales de la instrucción, las condiciones de una clara comprensión de su misión cívica ...a preparar a todas las mujeres del país, a fin de que el sufragio no les venga como una concesión inmerecida, sino como un reconocimiento a sus capacidades de ciudadanas. Así realizará a la vez la mujer el aprendizaje de la discusión sin bullas, sin alarmes, sin pasiones desbordantes, etc. Por que, ¿se imaginan los lectores, lo que sería una discusión de damas sobre asuntos políticos, si no se hubiera realizado antes el aprendizaje que permite hablar con serenidad, con sinceridad y con cordura? (p.5).

Otro de los discursos base por los cuales se le debe el voto a la mujer es al identificarla como madre, atribuyéndole características de procreadora y educadora de la patria ${ }^{13}$. Aquí merecen especial atención las preguntas planteadas por el diputado Gómez, en las cuales basa su fundamento para aprobar el voto:

¿Cómo es posible - espresó- que a esa artífice maravillosa le neguemos el derecho de escoger el Mandatario para sus propios hijos? ¿Cómo es posible negarle a la mujer - a la madre costarricense- participación en la escogencia de los hombres que habrán de gobernar al país, si su misión fundamental es la preparar ciudadanos aptos y honorables para la vida pública? (Cubillo, 1994, p.5).

Claro está que el discurso de la mujer como ente político, se dio bajo la gran sombra de la mujer como ama de casa, madre, esposa, hija. Su función como actriz política gira alrededor del elemento masculino, no como un ente propio.

Otra de las razones para su aprobación se vincula a lo retrograda de no hacerlo, como lo

$13 \quad$ Ruth Cubillo (1994) menciona: "En la cultura occidental, la mujer se caracteriza por desempeñar, primordialmente, una función ligada sin duda a la maternidad: el cuidado de los niños y del hogar" (p.50). indica el diputado Solórzano: "la negación del voto a la mujer - dijo — es resabio de prejuicios de los españoles del siglo XvIII. En los actuales momentos, negarles a las mujeres el derecho al sufragio, es simplemente sustraernos a las corrientes actuales" (Asamblea Legislativa, Archivado A39 E7623, p.6). El diputado Jiménez Quesada argumenta cómo las mujeres ya pagan impuestos y trabajan, por lo cual tienen derecho de saber quiénes van a administrar los dineros de sus contribuciones (Asamblea Legislativa, Archivado A39 E7623, p.6).

En la postura en contra del voto femenino, en dichos discursos básicamente se esgrimen dos razones. Primero, la corrupción que puede generar la política, al concebirla sucia y dañina, por lo cual la aprobación del voto podría dañar a la mujer, y segundo, el miedo de que la mujer salga de su hogar, tal como lo explicó el diputado Pinto:

... aclaró que, en lo que se refiere a capacidad, reconoce que existen muchas mujeres que superan al hombre, pero no cree que deben votar, pues no hay nada más sucio que la política y debemos hacer todo lo posible por mantenerlas al margen de la misma. Si se acuerda el voto femenino, ocurrirá que las madres van a abandonar a sus hijos, con los prejuicios familiares consiguientes (Asamblea Legislativa, Archivado A39 E7623, p.6).

Asimismo, la noticia del Diario de Costa Rica de parte del Sindicato de Maridos Oprimidos (S.M.O.), la nota es totalmente alarmante con respecto al hecho de que las mujeres voten, sobre todo por las consecuencias políticas de esto:

... es tan sensacional como digamos el lanzamiento de la primera bomba atómica, y cuidado no nos va a resultar el voto femenino una mera ATÓMICA, cuando la cosa se generalice y las mujeres cojan la política por su cuenta; $y$ como, según cálculos del censo, son más que los hombres, ahorita van a ver ustedes lo que es bueno, cuando vengan las próximas elecciones generales $y$ las mujeres lancen 
candidatas a diputadas $y$ candidatas a presidentas de la República (Asamblea Legislativa, Archivado A39 E7623, p.55).

La cita anterior permite ilustrar la percepción de algunos hombres con respecto al derecho al voto al considerarlo un elemento dador de poder $y$ libertad a la mujer, $y$ que posiblemente era el primer escalón para la intromisión de la mujer en la política.

Paralelo a los planteamientos a favor o en contra del voto femenino, se encuentran las discusiones y exposiciones sobre su obligatoriedad. En el discurso de José Figueres Ferrer se cuestiona la obligatoriedad para ellas, fundamentando que "hay muchas que prefieren su actual puesto en el hogar y desde allí, con su sabia cordura y su enorme pundonor cívico, impulsar a esos mismos seres para ella tan queridos hacia el recinto en donde se eligen a los conductores de la patria" (La sublime y heroica mujer costarricense cívicamente nos ha igualado, pero su voto debe ser optativo, 3 de junio de 1948, p.11).

Por su parte, Mireya Guardián de Varona y Ligia Herrera M., mujeres del Centro Femenino de Estudios ${ }^{14}$ hacen notar la importancia de imponer el voto obligatorio en las mujeres. Mireya basa su fundamento en el aspecto de la democracia, explicando:

... si se deja a la mujer en libertad de votar o no, habrá tantas abstenciones voluntarias que llegaríamos a ver desnaturalizada la esencia de la reforma política que nos otorgase el sufragio. (...) Con el voto femenino obligatorio se lograría la expresión, casi en su totalidad, del sentir de una gran masa ciudadana junto con la opinión de los electores del sexo masculino se obtendría, pues, la de toda la nación. Y esto es lo que quiere la Democracia bien entendida (Guardián, 9 de junio de 1948, p.7).

Mireya Guardián de Varona se identifica en su artículo como la fundadora del Centro Femenino de Estudios, creado el 18 de mayo de 1937.
Ligia, por su parte, defiende la obligatoriedad en base a la familia costarricense:

... al abogar en pro del voto optativo, ¿Se ha pensado en que puede haber casos de jefes de familia que se opongan al voto de la señora y las hijas, que quieran tomar parte en la elección de los que han de regir a la sociedad de que ellas son miembros y cuya labor buena o mala para esta sociedad han de sufrir directamente? Dado el concepto que en una gran mayoría del pueblo, sobre todo entre el campesinado existe acerca de los derechos de la mujer, el voto optativo podría entrañar un peligro para la tranquilidad del hogar costarricense (Herrera, 1948, p.11).

Las mociones de los diputados también reflejan las discusiones sobre la obligatoriedad del voto. En el acta 74, el diputado Mesa explica, "no podríamos, en modo alguno, afirmar esta última característica, porque si esta misma Asamblea va a establecer el sufragio femenino - se infiere de una fuerte corriente en ese sentido - no sabemos a ciencia cierta si va a ser obligatorio para las mujeres o no" (Asamblea Nacional Constituyente, 1949, p.175). La moción del diputado Trejos Flores, decía: "para agregar al artículo tercero el siguiente párrafo: es obligatorio para todo elector varón solicitar la inscripción en el Departamento Electoral del Registro Civil y emitir el voto en toda elección a que se convoque al pueblo. Para las mujeres esos actos son optativos" (Asamblea Nacional Constituyente, 1952, pp. 294-306).

Al respecto, el secretario de la Comisión redactora del proyecto de la nueva constitución es claro:

... no quiso la comisión consignar nada relativo al voto obligatorio o facultativo, para ambos sexos. En cuanto al hombre, por ser ésta cuestión muy debatida; $y$ en cuanto a la mujer, por la misma razón $y$ además porque se trata de un aspecto nuevo de nuestra vida política y porque un gran porcentaje de nuestras mujeres, hay que reconocerlo así, se oponen a que 
se les otorgue del derecho de sufragio (Morúa, 6 de agosto de 1948, p.11).

En este mismo folio se encuentran los telegramas enviados a la Asamblea Legislativa, a los disputados, al presidente del Congreso y a la Cámara Legislativa, de parte de mujeres y organizaciones, entre ellas, la Alianza Mujeres Costarricenses, Sección Femenina Partido Demócrata y Jefe de Empadronamiento Femenino Partido Liberación Nacional. Lo solicitado en dichos telegramas gira en torno a la igualdad para hombres y mujeres con respecto al derecho político de las últimas de ejercer el voto, ahora algunos de los telegramas rechazan la moción del diputado Trejos Flores con respecto al sufragio optativo para las mujeres. Para el año 1952, la evidencia demuestra que efectivamente estaba sobre la mesa del Congreso la discusión sobre la obligatoriedad del voto para las mujeres.

\section{DESPUÉS DE LA APROBACIÓN DEL SUFRAGIO FEMENINO}

El domingo 30 de julio de 1950, se da la primera votación de la mujer costarricense en un plebiscito para que los pobladores de los caseríos de la Tigra y la Fortuna decidieran su pertenencia al cantón de San Ramón o de San Carlos ¿Por qué en un plebiscito para decidir la anexión a un cantón? ¿Por qué en ese momento $y$ en esas condiciones? Eugenia Rodríguez (2003) en su artículo "Dotar de voto político a la mujer", menciona que se podría explicar por causas políticas, al pensar en ese primer voto como una condición ventajosa que serviría a las autoridades como un experimento de prueba con el voto femenino, con el fin de saber el número de votantes y su respuesta. Efectivamente, en el Diario de Costa Rica se encuentra la siguiente nota: "es un ensayo desde luego muy interesante, ya que no tiene precedentes en nuestro país y prácticamente servirá de experiencia para las próximas elecciones, en que habrán de tomar parte las mujeres" 15 (Comisión Interamericana de Mujeres, 1982, p.51).

15 Otras declaraciones para fundamentar: las elecciones plebiscitarias efectuadas el domingo pasado en los caseríos La Tigra y La Fortuna y en que por primera
Al contabilizados los datos, se observó que las mujeres concurrieron a las urnas más que los hombres:

... "traigo la más agradable impresión de este torneo cívico que considero de la mayor trascendencia en la vida institucional de la República" dice el delegado del tribunal electoral don Jorge Zamora: "Las mujeres conocían perfectamente sus funciones en ese día. Las autoridades del resguardo no tuvieron la menor intervención en ese histórico suceso" (Comisión Interamericana de Mujeres, 1982, p.59).

La votación realizada en el plebiscito no fue lo único en marcar un precedente histórico por llevar a las mujeres a votar, sino también el incluir mujeres en las peticiones realizadas a la Asamblea, un ejemplo es la petición de los vecinos de Cabeceras del Río La Muerte, El Tigre, Venado y Las Delicias para pertenecer al Cantón de Tilarán; la carta de agosto-setiembre de 1950 llevaba las firmas tanto de hombres como de mujeres (Ley nro. 1156, Asamblea Legislativa, 29 de abril de 1950).

Para el año 1952, lo más destacable es la reforma hecha al Código Electoral (Ley nro. 1536, Asamblea Legislativa, 10 de diciembre de 1952), siendo lo más significativo el cambio al artículo primero del capítulo uno del Título I, el cual dice: "son electores todos los costarricense de uno $\mathrm{u}$ otro sexo, mayores de veinte años e inscritos en el Departamento Electoral del Registro Civil" (p.14), y el Título vi sobre los derechos y deberes políticos, en su capítulo único llamado La Ciudadanía, art. 112, el cual indica: "la ciudadanía es el conjunto de

vez en Costa Rica participaron mujeres, con lo cual inició así la era del voto femenino en el país, han dado un resultado plenamente satisfactorio. Pusieron de manifiesto la mayor adaptabilidad del sexo femenino a deberes cívicos nuevos para ella, a la vez que su interés por los asuntos políticos ... la votación femenina del domingo pasado, realizada antes de que se termine el estudio de la reglamentación respectiva y de las consiguientes reformas al Código electoral, se llevó a cabo como un ensayo (Comisión Interamericana de Mujeres, 1982). 
derechos y deberes políticos que corresponden exclusivamente a los costarricenses por nacimiento o por adopción, de ambos sexos, que hayan cumplido 18 años de edad" (Ley nro. 1536, Asamblea Legislativa, 10 de diciembre de 1952, p. 14).

La mención específica al voto femenino se da en función de evidenciar que la participación de las mujeres "indefectiblemente aumentará bastante el número de sufragios" (Ley nro. 1536, Asamblea Legislativa, 10 de diciembre de 1952, p.88). Esta reforma es una consecuencia de la nueva constitución promulgada en 1949.

Relacionados con las modificaciones del Código Electoral, dos artículos del periódico La Nación demuestran los cambios necesarios a nivel de normativa. En uno se habla sobre "la obligación de portar la cédula de identidad será efectiva para las mujeres en Costa Rica a partir del primero de julio del presente año según disposición emitida por la Asamblea Legislativa" (A partir de julio las mujeres deben portar la cédula de identidad, 28 de marzo de 1952, p.3), el otro explica la sesión de la Asamblea en la cual se habló de "la imperiosa necesidad que tienen los organismos electorales de que se les asigne un mayor presupuesto para atender los compromisos adquiridos con el voto femenino" (Tampoco se resolvió ayer la ayuda para el voto femenino, 2 de abril de 1952, p.6).

El Diario de Costa Rica narra la labor llevada a cabo por el comité de empadronamiento de la Comisión Interamericana de Mujeres, "con un carácter apolítico diversas comisiones visitan fábricas, laboratorios, establecimientos comerciales y todos los lugares donde núcleos femeninos, aptos para la obtención de la cédula y su empadronamiento, no disponen del tiempo para tal objeto" (Intensa y patriótica labor desarrolla comité de empadronamiento de la Comisión Interamericana de Mujeres, 27 de marzo de 1952, p.3). En conclusión, tres años después de aprobado el sufragio femenino, se establecen todas las reformas necesarias para hacerlo real $y$ aplicar todos los requisitos para ejercer el voto.

Asimismo, no era cuestión solo de preparar las juntas, el dinero y los materiales; por ejemplo, el señor José Figueres publicó un campo pagado dedicado a las mujeres, otorgándoles responsabilidades sociales a ellas:

... para comenzar por la base, las mujeres de Costa Rica, que ahora entran al ejercicio pleno de la ciudadanía podrían tomar como lema, digno del corazón femenino, "la emancipación del jornalero". Otras mujeres magnánimas lucharon antes por la emancipación del esclavo (1 de abril de 1952, p.12).

Los cinco años de debates, discusiones, mociones, campos pagados $y$ discursos terminan el 26 de julio de 1953, cuando la mujer vota por primera vez para escoger las autoridades nacionales.

\section{CONCLUSIONES}

La década de los treinta fue muy convulsa debido al contexto internacional y nacional de crisis económica y del régimen capitalista imperante, estas condiciones propiciaron la participación más activa de las mujeres en la esfera política, con la vinculación por parte de algunas de ellas al Partido Comunista.

La Liga Feminista, así como, otras señoras y señoritas, preocupadas por la condición de la mujer costarricense hicieron esfuerzos para elevar al Congreso Constitucional peticiones para la aprobación del sufragio femenino, intentos en su mayoría archivados, sin embargo, tuvieron para la época el apoyo de algunos hombres intelectuales y políticos liberales progresistas.

Los argumentos generales mostrados en las cartas de petición se pueden resumir en los siguientes cinco aspectos:

1) Que no se puede establecerse comparación entre una mujer con cierto nivel educativo, consciente de las responsabilidades políticas de ejercer el voto, con hombres sin educación ni noción sobre las responsabilidades cívicas.

2) Existe en estas cartas un cuestionamiento de porqué Costa Rica con características que lo convierten en un Estado niega el voto a la mujer, cómo niega cubrirse 
del orgullo que llevaría la aprobación, cómo no busca una mejor orientación del país al incluir a todos sus miembros.

3) Creen que otorgar el sufragio femenino conllevaría a la mejora de las condiciones de las mujeres de las futuras generaciones, llevándolas a defender el Estado para resguardar la Constitución, la paz interior, las libertades $y$ las instituciones. En fin, la mujer llegaría a ser un baluarte de ayuda al hombre, más que un apéndice, para defender y mejorar el país.

4) La educación no basta para formar al ciudadano, debe dársele la responsabilidad de saber elegir y luchar para hacer un bien a la Patria y a la familia (se apela al término de la familia para hacer esa identificación de que la mujer cuida de la familia y debería también cuidar del Estado). De esta manera, apelan a elevar su nivel intelectual por medio del voto, así como, se aumenta la cantidad de votantes, cada sexo colabora en una Patria común y se eliminan las exclusiones. El voto ayudaría a probar las capacidades $y$ actitudes de la mujer, con lo cual demuestran que en cualquier campo pueden mantener en alto al país.

Con respecto a las discusiones de aprobación, se recalcan cinco puntos:

1) Los hombres creen que las mujeres merecen el voto debido a las actuaciones políticas del pasado, la actuación y la militancia en la dictadura de los Tinoco, la huelga de los brazos caídos y los acontecimientos de 1943. El voto se le otorgaría porque lo ganó en las luchas políticas.

2) Se apela a la educación de la mujer previo al voto, como la forma de obtener el máximo provecho al derecho del sufragio, ya que le permitirá a la mujer un voto informado $y$ responsable.

3) La obligatoriedad del voto tiene dos vertientes, por un lado, la democracia ${ }^{16} y$,

16 "Si se deja a la mujer en libertad de votar o no, habrá tantas abstenciones voluntarias que llegaríamos a por el otro, la mujer debe decidir, ya que de ella depende el ejercer el voto o impulsar a los varones de la "casa" a hacerlo.

4) En los discursos se reproducen los estereotipos sobre la mujer, su carácter de sumisa, de obediente, de incapaz de una conciencia política sin forjársela, de ama de casa, de esposa y de madre.

5) Es importante preguntarse el por qué la práctica política se creía sucia, corrupta $y$ dañina en la época (a no ser solo una justificación para no apoyar el voto de la mujer) y si en realidad se creía en la política como un elemento malo para la sociedad.

Con la aprobación del voto femenino, efectivamente hay un leve cambio de discurso con respecto a la mujer como sujeto político, aunque se seguía reproduciendo de cierta manera, su papel como esposa, madre, hija, obediente, sumisa y con libertad definida por las cuatro paredes de su hogar junto a su familia. Sin embargo, se debe tener presente que no se equivocó el Sindicato de Maridos Oprimidos, ya que el voto fue el primer paso de la mujer en su lucha por la igualdad y la equidad, aunque el camino no resultó fácil y aún se continua en su lucha.

\section{REFERENCIAS}

A partir de julio las mujeres deben portar la cédula de identidad. (28 de marzo de 1952). La Nación, p.3.

Archivo Nacional de Costa Rica [ANCR]. (s.f. a). Actas de la Asamblea Nacional Constituyente. Fondo Congreso, nro. 17114.

Archivo Nacional de Costa Rica [ANCR]. (s.f. b). Actas de la Asamblea Nacional

ver desnaturalizada la esencia de la reforma política que nos otorgase el sufragio ... Con el voto femenino obligatorio se lograría la expresión, casi en su totalidad, del sentir de una gran masa ciudadana junto con la opinión de los electores del sexo masculino se obtendría, pues, la de toda la nación. Y esto es lo que quiere la Democracia bien entendida" (Guardián, 9 de junio de 1948, p.7). 
Constituyente. Fondo Congreso, nro. 18811.

Asamblea Legislativa. (10 de diciembre de 1952). Ley nro. 1536. Código Electoral. San José, Costa Rica.

Asamblea Legislativa. (26 de setiembre de 1927). Ley nro. 15. Ley de Elecciones. San José, Costa Rica.

Asamblea Legislativa. (29 de abril de 1950). Ley nro 1156. Plebiscito de La Tigra y la Fortuna. San José, Costa Rica.

Asamblea Legislativa. (s.f.). Archivado A39 E7623, Archivo de la Asamblea Legislativa.

Asamblea Nacional Constituyente. (1949). Actas de la Asamblea Nacional Constituyente de 1949. Archivo Asamblea Legislativa.

Asamblea Nacional Constituyente. (1952). Actas de la Asamblea Nacional Constituyente de 1952. Archivo Asamblea Legislativa.

Casal, S. (1925). El voto femenino. Imprenta Nacional.

Chacón, M. C. (1984). Las mujeres del 2 de agosto de 1947 en la vida política del país. [Tesis para optar al grado de Licenciatura en Historia, Universidad de Costa Rica]. San José, Costa Rica.

Columna del Partido Social Demócrata. (2 de agosto de 1951). El Voto Femenino. La Nación, p.6.

Columna del Partido Social Demócrata. (20 de setiembre de 1951). La autonomía municipal. La Nación.

Columna del Partido Social Demócrata. (30 de agosto de 1951). Ayuda los damnificados de Paraíso y Orosí. La Nación, p.6.

Columna del Partido Social Demócrata. (9 de agosto de 1951). La Emancipación de la mujer. La Nación, p.6.

Comisión Interamericana de Mujeres. (1982). Algunos aspectos relativos al voto femenino. San José, Costa Rica: Ministerio de Cultura, Juventud y Deportes, Centro Nacional para el Mejoramiento de la Mujer y la Familia.

Cubillo, R. (1994). Las imágenes de la mujer en el Repertorio Americano. [Tesis para optar al grado de Magister Litterarum, Universidad de Costa Rica]. San José, Costa Rica.

Esperanzado el presidente Don Otilio Ulate en la dignificación de los procesos electorales (22 de octubre de 1951). La Prensa Libre, p.16.

Fernández, F. (1985). El voto femenino en Costa Rica: debates constitucionales 1917-1949 y la reforma constitucional de 1947. Asamblea Legislativa.

Figueres, J. (1 de abril de 1952). Carta a las Damas. La República, p.12.

Flores, A. L. (2001). Ni histéricas, ni reinas... ciudadanas: mujeres y politica en Costa Rica, 1940-1949. [Tesis para optar al grado de Magíster Scientiae en Estudios de la Mujer, Universidad de Costa Rica]. San José, Costa Rica.

Guardián, M. (9 de junio de 1948). No queremos voto optativo; queremos voto obligatorio o nada. La Nación, p.7.

Herrera, L. (11 de junio de 1948). La Prensa Libre, p.11.

Herrera, R. (2005). Maestras y militancia comunista en la Costa Rica de los años treinta. En E. Rodríguez (ed), Un siglo de luchas femeninas en América Latina. Editorial de la Universidad de Costa Rica.

Intensa y patriótica labor desarrolla comité de empadronamiento de la Comisión Interamericana de mujeres. (27 de marzo de 1952). Diario de Costa Rica, p.3.

La sublime y heroica mujer costarricense cívicamente nos ha igualado, pero su voto debe ser optativo (3 de junio de 1948). La Prensa Libre, p.11.

Morúa, E. (6 de agosto de 1948). Las mujeres costarricenses votaran en las elecciones populares. La Nación, p.11.

Quirós, L. (1 de julio de 1948). El Voto Femenino. Diario de Costa Rica, p.5.

Rodríguez, E. (2003). Dotar de voto político a la mujer, ¿Por qué no se aprobó el sufragio femenino en Costa Rica hasta 1949? Serie Cuadernos de Historia de las Instituciones de Costa Rica. Editorial de la Universidad de Costa Rica. 
Rodríguez, E. (2005). La lucha por el sufragio femenino en Costa Rica (1890-1949). En E. Rodríguez (ed), Un siglo de luchas femeninas en América Latina. Editorial de la Universidad de Costa Rica.

Solís, R. (3 de junio de 1948). ¿Será conveniente o no el Voto Femenino? La Prensa Libre, p.6.

Tampoco se resolvió ayer la ayuda para el voto femenino. (2 de abril de 1952). La Nación, p.6.
Ulate, O. (31 de mayo de 1948). Don Otilio Ulate aboga por que las mujeres puedan elegir $y$ ser elegidas en la próxima constituyente. La Prensa Libre, p. 1 y 8.

Fecha de ingreso: 17/07/2019

Fecha de aprobación: 18/12/2019 
